\title{
Lack of Maintenance Documentation or Guidelines
}

National Cancer Institute

\section{Source}

National Cancer Institute. Lack of Maintenance Documentation or Guidelines. NCI

Thesaurus. Code C72671.

Problem associated with user facility not receiving adequate service documentation, guidelines, or recommendations to perform preventative and corrective maintenance and performance assurance checks. 